\title{
Noémia de Sousa, ou ser "África da cabeça aos pés" em tempos de colonização
}

\author{
NOEMI ALFIERI \\ CHAM, Centro de Humanidade \\ Universidade Nova de Lisboa
}

\begin{abstract}
In the present essay, I examine the work and career of the Mozambican poet Noémia Carolina Abranches de Sousa Soares (1926-2002). It is well known that Sousa began her career publishing under the initials "NS" to confuse her identity with that of her brother (whose name was Nuno) and so obfuscate her gender; however, women are a constant element in her work. Beyond this, I argue that Sousa adopted a pioneering approach to gender, one deeply connected to the anti-colonial struggle, the fight for the rights of her people, and the African American imaginary. Indelibly linked to social, racial, and gendered subalternity, Mozambican women constitute in Sousa's oeuvre the personification of the struggle against the societal paradigms of the time.
\end{abstract}

Keywords: Anti-colonialism; Pan-Africanism; Mozambique; African poetry; women writers

Noémia Carolina Abranches de Sousa Soares, conhecida por Noémia de Sousa, nasceu no Katembe, Moçambique, em 20 de Setembro de 1926. ${ }^{1}$ António Paulo Abranches de Gama e Sousa, seu pai, tinha ascendência goesa, portuguesa e africana, enquanto a sua mãe, Clara Brüheim Abranches de Sousa (descrita pela própria Sousa como a "perfeita mestiça"), era filha de uma mulher da África do

\footnotetext{
${ }^{1}$ Gostaria de agradecer à Fundação para a Ciência e a Tecnologia (Portugal) pelo financiamento através da concessão de uma Bolsa de Doutoramento (SFRH /BD/114981/2016).
} 
Sul e de um alemão. As origens do casal, assim como a profissão de António, fizeram com que os seus filhos tivessem, desde muito cedo, contacto com as mais diversas personalidades que animavam aquele Moçambique ainda colonial. Tanto a profissão do pai, alto funcionário do Governo colonial, empregado no Banco Ultramarino, como as tradições da família da mãe tornaram a casa de estacas dos Sousa num lugar de encontro em que funcionários públicos, chefes tradicionais, pescadores goeses, intelectuais e comerciantes se encontravam e conviviam informalmente. Quando Sousa tinha seis anos de idade, a família mudou-se para Lourenço Marques.

A morte do pai, em 1932, implicou uma repentina mudança na vida da família. A mãe, que deixou de vestir as suas capulanas para evitar discriminações, não conseguindo fazer frente a todas as despesas que a educação dos filhos implicava, também não pôde mandar os filhos mais novos para Portugal. Foi assim que aos 16 anos, enquanto trabalhava, Sousa começou a estudar no curso pós-laboral de Comércio na Escola Técnica da então Lourenço Marques (Saúte 176), ${ }^{2}$ onde pela primeira vez a jovem moçambicana tomou consciência das crescentes discriminações raciais a que os negros e mestiços eram sujeitos. Em colaboração com o irmão Nuno e com outros jovens estudantes, publicou os seus primeiros poemas no jornal da escola, assinando simplesmente N.S., as duas letras que correspondiam com os nomes dela que menos eram conhecidos. "Poema ao meu irmão negro" originou assim certa confusão entre os futuros poetas Rui Guerra, Rui Knopfli e Virgílio de Lemos, que queriam saber de quem provinham aquelas palavras contundentes de denúncia, convencidos, obviamente, de que se tratava da caneta de um indivíduo de sexo masculino (Sousa, "Entrevista" 237-364).

Toda a sua poesia ficou dispersa em revistas moçambicanas e portuguesas como o Brado Africano; Itinerário; Notícias do Bloqueio; Mensagem (CEI); e Mshao até 2001, data em que a Associação de Escritores Moçambicanos a reuniu no livro Sangue negro, reeditado em 2016 pela Kapulana, no Brasil. A autora sempre se demonstrou reticente em aceitar as etiquetas de poeta, escritora e intelectual, para além de insistir na ideia de que a sua poesia se dirigia ao povo moçambicano, razão pela qual o formato do livro não se justificava. Antes de

\footnotetext{
${ }^{2} \mathrm{O}$ texto de Saúte constitui o prefácio da edição de Sangue negro da Associação de Escritores Moçambicanos, sendo posteriormente revista e actualizada para a edição brasileira.
} 
2001, recusou os convites à edição de Manuel Ferreira e Michel Laban, para depois ceder à insistência do amigo Nelson Saúte.

$\mathrm{O}$ desejo de anonimato, assim como a vocação a uma poesia universal e humanista, levou Sousa a publicar mais vezes sob pseudónimo: Vera Micaia começou a assinar poemas na "Página da mulher" do Brado Africano, jornal com o qual a autora colaborou com alguma intermitência entre finais de 1949 e o início de 1951. Estácio Dias e os irmãos Albasini (fundadores do bem conhecido jornal edito em Lourenço Marques) eram, de resto, amigos de longa data do seu já falecido pai, e não era com raridade que frequentavam a sua casa.

\section{Anti-colonialismo, resistência e exílio}

A colaboração com o Brado Africano foi interrompida pouco antes da partida de Sousa para a metrópole a bordo do paquete Angola, em Outubro de 1951. Devido a sua obra poética e à sua militância no MUD Juvenil de Moçambique, mas também por causa de um artigo que a autora tentou publicar no Brado sobre Eduardo Mondlane, ${ }^{3}$ a poeta já se encontrava sob a vigilância apertada da PIDE, como testemunha o processo em seu nome, número 2756 CI (2). João Mendes, o amigo com quem Sousa distribuía panfletos do MUD à noite, tinha sido preso, inspirando o "Poema de João." João, assim:

sofria com a passividade das mamanas do mudende, gemia com os negros amarrados ao cais, sentia o sol picando como piteiras aos meios dias dos pachiças, arengava com os chinas nas bancas do bazar, vendia com os monhés o verde desbotado das hortaliças, chorava com Marian Anderson spirituals vindos de Harlém. (Sangue negro 116-17)

\footnotetext{
${ }^{3}$ A escritora declarou a Laban que quis relatar o protesto que houve na Universidade de Witwatersand, em que Mondlane estudava. A tentativa de branqueamento da faculdade originou várias manifestações e protestos, uma destas para que o então jovem estudante moçambicano, a quem tinha sido negada a renovação do visto, pudesse continuar os seus estudos. Sousa conta que resolveu tentar escrever um artigo, apesar de saber que a censura não o iria deixar passar. Foi interrogada pela PIDE a seguir e descobriu, anos depois, que no mês em que Mondlane esteve preso pela PIDE em Moçambique, mesmo ele não sabendo nada do suposto artigo, foram-lhe feitas muitas perguntas sobre os seus contactos com a jovem poeta. Ver Laban (322-24).
} 
Invocando uma comunhão entre os povos e lutando contra as injustiças e as formas de opressão, a figura do amigo acabava por confundir-se com a própria ideia de Moçambique:

João e Moçambique confundiam-se

e João era jovem como nós.

João queria viver, queria conquistar a vida,

E por isso odiava as jaulas, as gaiolas, as grades,

E odiava os homens que as fizeram.

Porque João era livre,

João era uma águia e nascera para voar. (Sangue negro 117)

Após a prisão do companheiro, não ficava outra opção senão o exílio em Lisboa, que durou até 1964, proporcionando à autora contactos com a CEI, com o Centro de Estudos Africanos e a conhecida Casa da Tia Andreza (tia de Alda Espírito Santo, poeta são-tomense), onde fervilham os ideais independentistas e panafricanistas. Uma vez chegada a Portugal, a poeta moçambicana declarou ter descoberto com muito assombro de que aí as pessoas também sofriam, viviam a pobreza, conheciam a opressão: nunca antes quis acreditar no que o amigo Rui Guerra lhe dizia.

A criatividade poética de Sousa, porém, parecia ter ficado adormecida, uma vez que a escritora se encontrava longe da terra natal: o período de maior produção e publicação da sua obra circunscreve-se ao período entre 1949 e 1951. Já em Portugal, Sousa tornava-se num exemplo a seguir, uma referência poética e cultural incontornável: a "mãe dos poetas moçambicanos," como bem a definiu Zeca Afonso nas celebrações do 25 de Abril.

Surge com naturalidade, chegados a este ponto, uma pergunta: o que é que fez desta jovem que provinha do outro lado da Baía da cidade que hoje se chama Maputo numa personalidade que gozava de tanta visibilidade e respeito? Para além de ter sido uma das primeiras mulheres que, se bem que ainda influenciadas pelo contexto colonial, a este se opuseram de forma clara, através da denúncia das suas injustiças e da discriminação racial, Sousa foi antes de mais uma mulher cujo olhar se fixava na vida quotidiana dos habitantes dos subúrbios, na maioria africanos. Ao ler e descrever as paisagens moçambicanas, os cacimbos, a 
passagem rápida dos trabalhadores, das prostitutas, das pessoas comuns pelas ruas das cidades, a poeta tentou-se ler a si própria, esforçou-se em pôr em palavras o que o continente africano representava para ela, invocando uma irmandade entre os povos que muito devia ao imaginário feminino e a uma renovada forma de conceber a mulher e o seu ligar no mundo.

\section{O Brado Africano e o Mshao}

Não nos podemos esquecer de que a obra de Sousa e sua receção não foram isentas nem da (necessária) ideologização dos textos literários que caracterizou a sua época e as décadas sucessivas, nomeadamente a de ' 60 , nem da tentativa de fixar um possível cânone literário futuro, num contexto de descolonização e em vista da independência de Moçambique. Não queremos, com esta consideração, retirar valor à preciosa obra da autora, nem ao seu papel fundamental na consciencialização das gerações suas próximas, mas sim contextualizá-la, fazer uma delimitação ideológica e temporal do seu campo de acção. Entre o Acto Colonial estabelecido pelo Decreto no. 18570 de 8 de Julho de 1930, em que se definiam os territórios do Império Colonial Português e revisão constitucional de 1951, em que as colónias africanas, juntamente aos outros territórios então sob soberania portuguesa e sujeitas ao regime ditatorial do Estado Novo, passam a ser chamadas de "Territórios Ultramarinos," Moçambique viu a sua vida económica, social e cultural profundamente alterada. Nesta fase, os periódicos moçambicanos começaram a ser expressão não só de, como afirmado por Fátima Mendonça relativamente ao Brado Africano, "veículo de contradiscurso retórico como resposta a esse aparelho jurídico" (Mendonça 199), mas também a funcionar de catalisadores de um verdadeiro movimento político-cultural que visava desenvolver o sentido crítico, divulgar o conhecimento, promover, em suma, uma renovação cultural do panorama moçambicano.

Em 1948, constitui-se um novo espaço de abertura antecedente à candidatura do general Norton de Matos pela oposição. Nesta altura, Sousa começa a colaborar com o Brado Africano, onde acabará por publicar a maioria dos seus poemas e conhece Eduardo Mondlane que regressara da Universidade de Witwatersrand por não lhe ter sido renovado o visto de residência, situação que lhe motivara um artigo, que não chegou a ser publicado, por ter sido cortado pela

censura. É por esta altura que surge a tentativa em que se envolve igualmente 
Sousa com Dolores Lopez, de reagrupar jovens da Associação Africana e do Centro Associativo dos Negros de Moçambique como forma de recuperar os mecanismos identitários formulados anteriormente e que, com as ressonâncias das explosões nacionalistas na Ásia e em África, alargava o sentimento de resistência ao colonialismo (Mendonça 207).

Tal como o Brado, a revista Mshao, em que Sousa colaborou com a publicação do "Poema da infância distante" e cujo único número saiu em 1952, propunha uma renovação cultural, profundamente radicada, neste caso, nas tradições moçambicanas e na referência metafórica aos costumes do povo Chope como alegoria do inteiro povo moçambicano. ${ }^{4}$ Maria de Santa-Cruz salientou, a este propósito, que "embora a polícia política ainda não se tivesse instalado em Moçambique, bastaria o título para alertar as censuras administrativas, que então se licenciavam em Lisboa com programas de psicologia, línguas bantas e alguma informação sobre as tradições populares de menor secretismo" (Santa Cruz, 17). Como observou Cremildo Baulhe, é preciso realçar:

Um detalhe: Msaho, é uma festa do povo Chope, que é feita para recriar o surgimento da etnia, para comemorar a sua vitalidade e fazer acções de graças aos seus deuses pelos bons acontecimentos que aconchegaram a comunidade (e.g.: chuvas, fartura na colheita e uma vigorosa natalidade). Os Chopes (habitantes do sudoeste de Moçambique) durante a festa do Msaho, tocam (kuveta, em Xitxopi) a Timbila (plural da m’bila, nome que essa etnia dá ao Xilofone) e dançam (Kussinha, dançar em Xitxopi) para exteriorizar a sua alegria. Mas, também o Msaho é feito em momentos de crise, de pranto, de fome, de choros e dúvidas existenciais que atrapalham qualquer sociedade. Me aproximando a Toro (33) diria que o Msaho 'é um sistema de integração humana, de renovação orgânica, de reeducação afectiva e de

\footnotetext{
${ }^{4}$ Conforme indicado em Ferreira, "Nesse primeiro número (e afinal o único) há o registo de oito poetas: Alberto Lacerda, Domingos de Azevedo, Duarte Galvão, Sousa, Ruy Guerra, Augusto dos Santos Abranches, Cordeiro de Brito, Reinaldo Ferreira. Todos eles, ou pelo menos alguns deles poetas de nível estético indiscutível. Simplesmente acontece que, por exemplo, os três últimos eram portugueses radicados e, com excepção de A. dos Santos Abranches, não estavam empenhados na construção de uma poesia de características específicas" (74).
} 
reaprendizagem das funções originais da vida.' É nesta plataforma de oscilação-de partes boas e más — que se assenta o Msaho.

O "Poema da infância distante," escrito em 29 de Outubro de 1950, inseria-se assim na lógica da reapropriação das raízes e, ao mesmo tempo, da denúncia poética das iniquidades e injustiças às que o povo se encontra, mais uma vez, sujeito. Misturam-se as lembranças dos "companheiros acocorados na roda maravilhada / e boquiaberta de 'Karingana wa karingana' / das histórias da cocuana do Maputo" com a visão do "vento uivando no telhado de zinco, / o mar ameaçando derrubar as escadas de madeira da veranda / e casuarinas, gemendo, gemendo, / oh inconsolavelmente gemendo, / acordando medos estranhos, inexplicáveis / nas nossas almas cheias de xituculumucumbas desdentadas / e reis Massingas virados jibóias" (Sangue negro 53). ${ }^{5}$

A memória da comunhão é a prova de que "fraternidade não é mera palavra bonita / escrita a negro no dicionário da estante" (Sangue negro 54), pois apesar do sofrimento do povo moçambicano, da ligação íntima da poeta com "os gritos dos negros dos botes / chamando as mamanas amolecidas de calor, / de trouxas à cabeça e garotos ranhosos às costas / soavam com um ar longínquo, / longínquo e suspenso na neblina do silêncio. / E nos degraus escaldantes, / mendigo Mufasini dormitava, rodeado de moscas" (Sangue negro 51).

\section{Negritude, Pan-Africanismo e contexto moçambicano}

Tendo sido frequentemente associada com o movimento da Negritude inaugurado por Aimé Césaire e Léopold Senghor, Sousa, apesar de falar correntemente, para além do ronga e do português, também o francês e o inglês, parece nunca ter tido acesso directo às obras do antilhano e do senegalês. As suas referências literárias e culturais teriam sido, para além da tradição oral moçambicana, Jorge Amado (incontornável para os jovens da sua geração), Nicolás Guillén e, como evidente no "Poema a João" e em "Deixa passar o meu povo," os spirituals negros de Harlem, assim como a obra de Billie Holiday, que

\footnotetext{
${ }^{5}$ A cocuana é a avó, enquanto o Karingana wa karingana o equivalente do "Era uma vez." Há, portanto, uma explícita e voluntária referência à tradição oral moçambicana. A casuarina é uma árvore com aspecto parecido ao de um pinheiro, muito difusa na zona costeira da Baía de Maputo. As xituculumucumbas são seres espirituais.

Poderia talvez interpretar-se neste sentido a comparação que Sousa estabelece entre os reis Massingas e as gibóias (serpentes).
} 
em 1939, com "Strange Fruit," já tinha chamado a atenção para a condição dos afro-americanos. Explica-se, assim, a vocação universalizante da obra da escritora moçambicana, que estava certamente radicada no seu tempo e na situação socio-política do seu país, mas que não se limitava só e exclusivamente ao âmbito da libertação política de Moçambique.

Umas das características que foi apontada à produção poética de Sousa foi que, como aconteceu com muitas mulheres da sua geração e das seguintes, a representação da condição feminina e o esforço na afirmação da identidade das mulheres suas contemporâneas dificilmente podem ser abstraídos do contexto da luta anticolonial. Neste contexto de subalternidade dentro da subalternidade, a poesia da Sousa contrasta o estereótipo pelo qual, como afirma Hilary Owen, "Women, it would seen, must be either feminist or anticolonial" (49).

A relutância em propor uma representação da imagem feminina completamente aderente ao estereótipo anticolonial, tal como acabará por ser elaborado pela FRELIMO, torna o caso da nossa poeta numa oportunidade de reflexão particularmente interessante. Várias são as ligações que podem ser tidas em consideração a este propósito: a recepção do imaginário luso-tropicalista na época, o papel da mulher na construção nacional na óptica da FRELIMO e no discurso de Samora Machel e, última mas não por isso menos relevante, a tensão entre uma imagem da mulher africana quase pré-idílica, mitologizada, e ao mesmo tempo a prepotente presença do concreto, do corpóreo. Tal como nós será possível comprovar, e como bem esclarecido por Owen, a obra da poeta poderse-ia enquadrar num contexto de hibridez, sendo a mestiçagem e as ameaças da assimilação cultural duas grandes preocupações que animam esta producção poética.

O ideário luso-tropical na acepção da adaptação que o Estado Novo fez da obra de Gilberto Freyre visava contrastar e reduzir, pelo menos a nível de convivência cultural, os contrastes raciais - que geravam muita preocupação nas colónias portuguesas em África e que ameaçavam, sobretudo, comprometer a continuidade política económica do império.

O contexto moçambicano, naturalmente distinto do dos restantes territórios sob controlo português (por estar voltado para o Índico, pela sua proximidade com a África do Sul e pela mobilidade de pessoas e pela coexistências das inúmeras culturas que o populavam), não deixou de se deixar fascinar por uma ideologia que assentava na convivência de várias culturas, apesar de esta 
convivência implicar uma implícita, mas marcada, superioridade cultural e racial dos portugueses. A difusa mestiçagem e o desejo de mudança, mas ao mesmo tempo de manutenção de privilégios adquiridos, assim como o comprometimento de algumas franjas da população para uma progressiva inclusão dos assimilados nas elites locais, favoreceram uma certa popularidade de alguns conceitos que assentavam no luso-tropicalismo.

Nos anos '50, de facto, este imaginário gozava de alguma popularidade em Portugal, mesmo entre os ambientes de esquerda moderada, e acabou por ter certo papel no desenvolvimento dos ideais anticoloniais. Isto deveu-se provavelmente ao facto de que a teoria propunha uma visão que já em si propunha uma metamorfose da práctica colonial, se bem que não implicando igualdade. Naquela altura, pouco depois do fim da Segunda Guerra Mundial, a iminência da mudança estava bem clara para o regime e oposição, aos funcionários do governo como às classes médias urbanas (ainda mais às das colónias). O governo preocupava-se em travá-la, Salazar em adaptar-se à nova configuração do Mundo sem que Portugal perdesse a sua área de influência, as novas classes e grupos sociais surgidos nas colónias em reconfigurar o seu lugar na sociedade, sem que nenhum destes intervenientes tivesse realmente claro como o fazer, num cenário de geral incertidão e caracterizado por muitas incógnitas.

\section{Quotidiano feminino e denúncia da subalternidade}

Quando analisada neste contexto mais amplo, sem projectarmos na abordagem à obra a mentalidade nossa contemporânea, os valores que são comummente dados por adquiridos no século XXI e os eventuais juízos de valor a eles associados, a poesia de Sousa é inovadora. Inovadora não só por ser escrita por uma mulher, mas também porque é a mulher-especificamente a mulher negra com um forte vínculo à tradição popular e oral moçambicana, à terra e às paisagens de Moçambique - que se torna, na maioria dos poemas, protagonista.

A autora tenta não só dar espaço e visibilidade a uma parte da sua ancestralidade e da sua história familiar que ameaçava desaparecer por força da assimilação e da conjuntura histórica em que vivia, mas também reiterar a 
invocação à fraternidade e ao sentido de unidade do seu povo. ${ }^{6} \mathrm{O}$ recurso frequente à imagem da Mãe Negra ou da Mãe África acaba, assim, por ser tanto uma reivindicação identitária como, mais uma vez, uma forma de luta contra os paradigmas da sociedade do seu tempo:

Mesmo na igreja o negro tinha que ficar lá para trás, nos bancos de trás; nos autocarros, aquele banco corrido, assim de trás, era para eles, não podiam vir à frente. Nós eramos descendentes de colonos, nós mestiços tínhamos direito a ficar em qualquer lugar, mas eu via os outros lá atrás. Eu via a mulher grávida negra que ficava de pé e se não fosse um dos negros a dar-lhe o lugar ninguém lhe dava; mas a senhora branca que entrava, tinha logo, fosse quem fosse, alguém que se levantasse para lhe dar o lugar, grávida ou não grávida [...]. E nos cinemas era tudo dividido também. Mais tarde, quando começam a aparecer os assimilados, começam a poder ir ao cinema, mas ficavam no que chamavam lá a galeria, o galinheiro, lá em cima, sem mistura com os outros; não, não podiam entrar pela mesma porta, entravam pela porta que dava para ali, não se podia misturar com os outros. (Sousa, "Entrevista" 268-69)

A própria vivência da vida da cidade acabava, de facto, por ser mais uma das razões na origem do sofrimento de mulheres cujas condições de vida já eram precárias, e que pela cidade e pelo significado simbólico que ela tinha, o de lugar dinâmico e frenético, se sentiam irremediavelmente atraídas. Através da utilização do nós poético, afirma Sousa em "Moças das docas" que "somos fugitivas de todos os bairros de zinco e caniço" (79):

Fugitivas das Munhuanas e dos Xipamanines, viemos do outro lado da cidade com nossos olhos espantados,

\footnotetext{
${ }^{6}$ Em entrevista a Michel Laban, Sousa afirmou, por exemplo, que pouco antes da morte do seu pai, a mãe foi obrigada a abandonar as capulanas, para evitar a discriminação racial. Lembra, também, o esforço da sua mãe e das suas tias (que sempre andaram de capulana e lenço) em manter vivas as tradições africanas (252-53)
} 
nossas almas trançadas,

nossos corpos submissos escancarados.

De mãos ávidas e vazias, de ancas bamboleantes lâmpadas vermelhas se acendendo, de corações amarrados de repulsa, descemos atraídas pelas luzes da cidade, acenando convites aliciantes como sinais luminosos na noite,

Viemos ...

Fugitivas dos telhados de zinco pingando cacimba, do sem sabor do caril de amendoim quotidiano, do doer de espádua todo o dia vergadas sobre sedas que outras exibirão, dos vestidos desbotados de chita, da certeza terrível do dia de amanhã retrato fiel do que passou, sem uma pincelada verde forte falando de esperança, (Sangue negro 92-93)

O insistir da autora na condição de subalternidade das raparigas que retrata, assim como a tentativa de universalização das suas penas quotidianas, não implica, porém, que as preocupações à volta do género e da condição feminina fossem necessariamente subordinadas às questões sociais e à luta contra a injustiça. A escrita de Sousa é marcadamente feminina não pelo que denuncia, mas pela solução que oferece: o feminino-irrevogavelmente associado à África e à imagem de Mãe África é fonte de coesão (como acontece com as cocuanas do "Poema da infância distante"), de força e esperança, apesar de esta última acabar por ser, muitas vezes, desiludida:

Sob o chicote da esperança, nossos corpos capulanas quentes embrulharam com carinho marítimos nómadas de outros portos, saciaram generosamente fomes e sedes violentas... Nossos corpos pão e água para toda a gente. (Sangue negro 93) 
Entram em jogo, neste trecho, não só uma clara alusão à colonização e a atitude das mulheres perante os homens europeus, mas também uma rompente corporeidade e, sobretudo, uma invocação ao instinto de proteç̧ão, quase materno, que muito condiciona a condição feminina. Inspirado no poema homónimo escrito por Duarte Galvão, heterónimo de Virgílio de Lemos, o poema de Sousa é uma reacção contra a representação que o poeta fez da prostituição: "uma coisa horrorosa," afirmou a moçambicana a Laban, "ele fez daquilo uma coisa muito bonita. O Virgílio de Lemos era, naquela época, um menino muito diáfano, muito católico, muito cumpridor de tudo. E depois teve uma viragem e então escrevia outras coisas." (Sousa, "Entrevista" 313). A concepção de mulher que a escritora representa só pode ser compreendida na sua inovação se considerarmos a época histórica em que se insere pois a mulher, apesar de ainda estar imersa nas funções sociais que the são tradicionalmente atribuídas, reivindica o direito a ter outros papéis, a decidir da sua vida por ela própria, como acontece em "Poema," inspirado numa confronto que a amiga Irene teve com a sua mãe. Dando voz à amiga da poeta, o poema insurge contra o papel atribuído a algumas jovens mulheres na sociedade colonial:

Mãe:

Por que foi que me encerraste na alvenaria desse quarto fechado a todo o mundo, por que me ergueste muros protectores e me separaste de meus irmãos e me ataste fitas azuis no cabelo? (Sangue negro 64)

A raiva e a tristeza da jovem, que viu passar à porta da sua casa um "estranho grupo de olhos visionários, / sacudindo sacas esfarrapadas, /de pés gretados cobertos de lama dos caminhos / e bocas rasgadas entoando canções" (Sangue negro 63), anseia a liberdade e espírito de coesão que sempre lhe foram negados:

Porquê, Mãe?

Porque me defendeste no egoísmo do teu amor

e me afastaste do perigo do lá fora?

Oh, Mãe, porque me arrancaste à Vida? 
O teu egoísmo transformou-me em cadáver de laços no cabelo e vestidos de seda e paredes de alvenaria servindo de jazigo...

E eu queria, oh queria ir, nua, no grupo estranho que me passou à porta, soltando ao luar canções salgadas de esperança e cabeças se desgrenhando ao vento... (Sangue negro 64)

Dos 46 poemas que compõem Sangue negro, só três estavam dispersos, enquanto os outros quarenta e três já tinham sido incluídos numa versão mimeografada que circulou em Lourenço Marques entre 1949 e os primeiros anos 50. Muitos deles eram, na altura, inéditos. A obra, que para a sua autora sempre foi considerada uma não-obra, um conjunto incompleto de poemas não concluídos e muitas vezes escritos "de um jeito," ou por causa de uma das suas "fúrias," sentidas reacções a representações que não lhe pareciam fazer justiça ao seu povo, tem como um dos seus fios condutores o tema feminino e o contraste entre branco e preto. Em «Nossa irmã lua» a personificação feminina do astro é meiga, protege os homens (ou irmãos) "com a quentura terna e gostosa / do seu carinho," enfeitiçando-os e proporcionando o sono e o cante amoroso à lua. Isto não elimina, contudo, a amargura sentida pelo nós poético: "Só não compreendemos / como é que, sendo tão branca a lua nossa irmã, / nos possa ser tão completamente cristã, / se nós somos tão negros, tão negros, / como a noite mais solitária e mais desoladamente escura" (Sangue negro 36). É a própria lua que, em "Súplica," ilumina as “noites mulatas da selva moçambicana" (Sangue negro 37), resultando mais uma vez na semi-personificação da mulher na paisagem de Moçambique. Provada pelas injustiças, a Mãe de "Deixa passar o meu povo" é "minha Mãe de mãos rudes e rosto cansado" acaba por ser tanto a mãe da poeta como a Mãe África ou, mais simplesmente, uma e todas as mães de Moçambique. É mais um exemplo de tentativa de universalização que é explicitada no poema "Apelo," em mais uma chamada à perpetuação da vida no seio do continente:

Ó África, minha mãe-terra, diz-me tu:

Que foi feito da minha irmã do mato, que nunca mais desceu à cidade com seus filhos eternos (um nas costas, outro no ventre), 
com seu eterno pregão de vendedora de carvão?

Ó África, minha mãe-terra,

ao menos tu não abandones minha irmã heróica,

perpetua-a no monumento glorioso dos teus braços! (Sangue

negro 96)

Não podendo abstrair-se da sua condição feminina, querendo invocar aquela esperança que a perpetuação da vida e a continuidade entre gerações podia representar pelo seu país, Sousa, já em 1949, sonhava com a independência e gritava, num dos poemas que acabou por consagrá-la no mundo poético ("Se me quiseres conhecer”) "Torturada e magnífica, / altiva e mística, /África da cabeça aos pés, /—ah, essa sou eu!” (Sangue negro 49).

\section{Conclusão}

A poeta cuja obra foi incluída em muitos manuais de formação de combatentes da FRELIMO, que em 1969 era canonizada pela revista Mozambique Revolution, órgão oficial sempre da FRELIMO, não participou na festa com que sempre sonhou. No 25 de Junho de 1975, de facto, Sousa encontrava-se na sua casa em Cascais, assistindo ao discurso de Samora Machel pela televisão na companhia de Eusébio, a pantera negra do Benfica, e de outros amigos.

Conforme o que declarou posteriormente, não só não tinha sido convidada para a festa. Já desde a sua estadia em Paris, em Moçambique circulavam vozes que a faziam "podre de rica," uma pessoa que já não queria saber de lutas e de África. Não a vendo na festa, houve quem, como Fonseca e Costa, se dirigisse directamente a Marcelino dos Santos pedindo explicações. Para todos os efeitos e apesar de Sousa ter declarado, até à data da sua morte, nunca ter recebido o convite que tanto teria desejado, ela foi convidada, recusou, e vozes circularam dizendo que ela até pediu uma indemnização (Sousa, "Entrevista" 343-44).

Só voltou a Moçambique anos depois de 1975, muito emocionada e comovida. Nesta ocasião, afirmou à filha Virgínia, que a acompanhava: "Nunca pensei que alguma vez visse um negro andar na minha terra com ar de que a terra lhe pertence" (Sousa, "Entrevista" 149). Morreu em Cascais, Portugal, em 4 de Dezembro de 2002. 


\section{Obras citadas}

ANTT/ PT/ /PIDE/ PROC 2756 CI (2) NT 7229, Carolina Noêmia Abranches de Sousa, 76 folhas.

Bahule, Cremildo. "Literatura moçambicana: um mshao em sedimentação." Jornal de Notícias, 5 Nov. 2012, www.jornalnoticias.co.mz/index.php /caderno-cultural/5870-literatura-mocambicana-um-msaho-emsedimentacao.html.

Ferreira, Manuel. Literaturas africanas de expressão portuguesa, vol. 2, Bertrand, 1997.

Howen, Hilary. Mother Africa, Father Marx: Women's Writing of Mozambique, Bucknell UP, 2007.

Mendonça, Fátima. "Dos confrontos ideológicos na Imprensa em Moçambique." Os outros da colonização: ensaio sobre o colonialismo tardio em Moçambique, Imprensa de Ciências Sociais, 2012, pp. 193-220.

Miranda, Eduardo. "Do direito consuetudinário à propriedade privada $-\mathrm{O}$ caso da comunidade rural Matsolo-Aldeia de Djuba, distrito de Marola, Província de Maputo, Moçambique.” Africanologia, no. 1, 2008, www. recil.grupolusofona.pt/handle/10437/109.

Santa-Cruz, Maria de. Timbila de ossos e sonho: Msaho e outros cantares: a guerrilheira poesia e a chamada 'poesia de combate.' Apenas, 2009.

Saúte, Nelson. "A mãe dos poetas moçambicanos." Sangue negro de Noémia de Sousa, Kapulana, 2016, pp. 175-82.

Sousa, Noémia de. "Entrevista por Michel Laban.” Moçambique, encontro com escritores, vol. 1, Fundação Engenheiro António de Almeida, 1998, pp. 236346.

—. Sangue negro. Associação de Escritores Moçambicanos, 2001.

Toro, Rolando. Biodanza. Olavobrás, 2002. 